\title{
Diabetic neuropathy: A narrative review of risk factors, classification, screening and current pathogenic treatment options (Review)
}

\author{
ANDREI BONDAR ${ }^{1,2}$, AMORIN REMUS POPA $^{1,2}$, NIKOLAOS PAPANAS ${ }^{3}$, \\ MIHAELA POPOVICIU ${ }^{1,2}$, COSMIN MIHAI VESA ${ }^{1,2}$, MONICA SABAU $^{1,2}$, CRISTIAN DAINA $^{1,2}$, \\ ROXANA ADRIANA STOICA ${ }^{4}$, NIKI KATSIKI ${ }^{5}$ and ANCA PANTEA STOIAN ${ }^{4}$ \\ ${ }^{1}$ Department of Psychiatry, Clinical County Emergency Hospital of Oradea, 410169 Oradea; \\ ${ }^{2}$ Faculty of Medicine and Pharmacy, University of Oradea, 410073 Oradea, Romania; \\ ${ }^{3}$ Second Department of Internal Medicine, 'Democritus' University of Thrace Diabetes Centre, \\ 68100 Alexandroupolis, Greece; ${ }^{4}$ Department of Diabetes, Nutrition and Metabolic Diseases, \\ 'Carol Davila' University of Medicine and Pharmacy, 050474 Bucharest, Romania; \\ ${ }^{5}$ Second Propaedeutic Department of Internal Medicine, AHEPA University Hospital, 54636 Thessaloniki, Greece
}

Received January 22, 2021; Accepted February 22, 2021

DOI: $10.3892 / \mathrm{etm} .2021 .10122$

\begin{abstract}
Diabetic neuropathy (DN) is a frequent complication of diabetes mellitus (DM) with severe consequences as it progresses and influences all human body systems. This review discusses the risk factors for DN, the main characteristics of the clinical forms of DN, the screening methods and the current therapeutic options. Distal symmetric DN is the primary clinical form, and DM patients should be screened for this complication. The most important treatment of DN remains good glucose control, generally defined as HbA1c $\leq 7 \%$. Symptomatic treatment improves life quality in diabetic patients. Pharmacological agents such as alpha $(\alpha)$-lipoic acid and benfotiamine have been validated in several studies since they act on specific pathways such as increased oxidative stress $(\alpha$-lipoic acid exerts antioxidant effects) and the excessive production of advanced glycosylation products (benfotiamine may inhibit their production via the normalization of glucose). Timely diagnosis of DN is significant to avoid several complications, including lower limb amputations and cardiac arrhythmias.
\end{abstract}

\section{Contents}

1. Definition and risk factors

2. DN classification and diagnosis

Correspondence to: Dr Roxana Adriana Stoica, Department of Diabetes, Nutrition and Metabolic Diseases, 'Carol Davila' University of Medicine and Pharmacy, Street Ion Movila 5-7, 050474 Bucharest, Romania

E-mail: roxana88stoica@gmail.com

Key words: diabetic neuropathy, sensory neuropathy, $\alpha$-lipoic acid, benfotiamine, diabetes mellitus, diabetic foot
3. Current treatment options

4. Experimental treatment

5. Suggestions for a therapeutic approach

6. Conclusions

\section{Definition and risk factors}

Diabetic neuropathy (DN) may be defined as the presence of certain signs or specific symptoms and suggestive for neuropathy in patients with diabetes mellitus (DM), after excluding other possible causes of neuronal damage (1). DN is the most common microvascular complication encountered in DM individuals; after 20 years of disease progression, more than $50 \%$ of DM patients are affected by this complication with a significant impact on their life quality, considering the characteristic chronic pain in their lower limbs (2). DN currently remains an important cause of morbidity. It is a recognized risk factor for diabetic foot syndrome and falls generated by balance disorders, especially in the elderly (3). Diabetic foot syndrome is also associated with a high risk of infection and amputation (3). DN prevalence significantly differs in observational studies due to the varying diagnostic methods used. In a UK study (4), $22.7 \%$ of individuals with type $1 \mathrm{DM}$ had $\mathrm{DN}$; also, $65 \%$ of DM patients treated with insulin, and $59 \%$ of patients on oral antidiabetic drugs have DN. Other studies demonstrated that the DN prevalence in patients with type 2 DM was $32.1 \%$ (5). In young diabetic patients, its prevalence is $7 \%$ in type $1 \mathrm{DM}$, and $22 \%$ type $2 \mathrm{DM}$, respectively (6). In Romania, the prevalence of self-reported DN was estimated to be around $79 \%$ in a population of 21,261 patients. That study included both type 1 and type 2 diabetes patients and did not further analyze the prevalence according to diabetes type (7).

Distal DN, the most common form, accounts for $75 \%$ of all DN cases. The 'American Diabetes Association' (ADA) recommends physicians involved in DM screen for DN at five 
years after the DM type 1 debut, and at the time of diagnosis in individuals with type $2 \mathrm{DM}(8)$. Screening for DN is of high importance since approximately $50 \%$ of patients with DN are asymptomatic (8). DN increases the risk of lower limb amputations by 1.7-fold; in the presence of a leg deformity, the risk increases by 12 -fold, whereas in cases with a history of lower limb ulceration, the risk increases by 36 -fold (9). This increased frequency of lower limb amputations in patients with DM and $\mathrm{DN}$ is attributed to lower limb micro-traumatisms, due to the fact that affected individuals have diminished pain sensation. Another form of DN, cardiac autonomic neuropathy, is associated with extremely high 10-year mortality of $25-50 \%$, mainly due to the generation of cardiac arrhythmias (10). The most investigated and documented predictor factors for the development of DN are hyperglycaemia, DM duration and age, as well as the presence of microvascular complications including hypertension, dyslipidaemia, diabetic retinopathy and chronic kidney disease (11).

Hyperglycaemia is an essential factor in the onset and progression of DN (1). The finding is highly specific in individuals with type $1 \mathrm{DM}$ but incompletely validated in those with type 2 DM. The 'Diabetes Control and Complications Trial' (DCCT) (12) followed subjects with type $1 \mathrm{DM}$ for 6.5 years, who underwent either intensive treatment of hyperglycaemia or standard treatment (12). In the intensive treatment group, DN was developed significantly less frequently, whereas, in those who already had DN, its progression was slower (12). This considerable impact of high blood glucose levels on the risk of DN was demonstrated by the finding that a $2 \%$ elevation of HbA1c correlated with an increase in DN frequency by $20 \%$ (13). Another study performed on 3,000 subjects with type $1 \mathrm{DM}$ showed that the prevalence of $\mathrm{DN}$ in patients with $\mathrm{HbA} 1 \mathrm{c}<5.4 \%$ was $15 \%$, while in those with HbAlc $>7.8 \%$ it was $40 \%$ (14). Similarly, a meta-analysis revealed that optimal blood glucose control decreases the incidence of DN in types 1 and $2 \mathrm{DM}$ individuals. In type $1 \mathrm{DM}$ the risk reduction per year was $1.84 \%$ (95\% CI: $1.11-2.56, \mathrm{P}<0.01)$, while in individuals with type $2 \mathrm{DM}$ the annual risk reduction was $0.58 \%(95 \%$ CI: 0.01 to $-1.17, \mathrm{P}=0.06)(15)$. It can be observed that in type $1 \mathrm{DM}$ the DN risk is reduced, while in type 2 the decrease is not statistically significant, which means that additional risk factors influence to the development and evolution of DN in type 2 DM (15). The Addition-Denmark study (16) and the 'Action to Control Cardiovascular Risk in Type 2 Diabetes' (ACCORD) study (17), with a large number of type 2 DM patients $(n=10,251)$, also failed to prove any positive results of intensive blood-glucose control on the reduction of distal DN incidence or prevention of cardiac autonomic neuropathy. The Steno-2 study demonstrated no effects of blood glucose control on the risk of developing somatic DN but found a significant decrease in the risk of developing cardiac autonomic neuropathy with HR 0.37 (95\% CI: 0.18-0.79, P<0.01) (18).

Previous findings showed that, the choice of antidiabetic treatment may play a role in the rate of DN occurrence. In the 'Bypass Angioplasty Revascularization Investigation 2 Diabetes' (2D BARI) study (19), information regarding DN presence was available for 2,314 of 2,368 patients. This large number of patients was divided into groups according to their diabetes mellitus therapy, 1,669 patients received non-insulin therapies (metformin and/or thiazolidinedione or a sulphonylurea), while 645 received insulin therapy. After adjusting for multiple cofactors such as HbA1c and DM duration, the risk of DN remained over $30 \%$ higher in patients who were taking insulin compared to patients who were not taking insulin (OR=1.34, 95\% CI 1.08-1.67) (19).

Hypertension is the most important and also an independent risk factor for DN (20). Experimental studies compared the impact of hypertension on nerve function in rodents with streptozotocin-induced DM. Both groups of DM rodents with and without hypertension showed thermal hyperalgesia, decreasing nerve conduction, nerve ischemia and axonal atrophy. The group with hypertension and DM showed thinly myelinated nerve fibres with supernumerary Schwann cells and decreased nerve levels of myelin basic protein. These alterations were not present in rodents without hypertension. Overlapping diabetes on hypertension led to modifications in nerve blood flow, conduction, axonal atrophy or nerve ischemia, and increased the ratio of the thinly myelinated fibres (21).

Dyslipidaemia is another risk factor that can contribute to the development of DN since high levels of total cholesterol, triglycerides, low-density lipoprotein cholesterol (LDL-C) and high-density lipoprotein cholesterol (HDL-C) are associated with an increased risk of neuropathy. Of all the lipid fractions, triglycerides have the most significant effect on the risk of neuropathy (22). In this context, fibrate and statins may reduce DN occurrence (23). The presence of smoking is also associated with increased DN prevalence (24). Indeed, the frequency of DN was related to the number of packs of cigarettes smoked per year (24). There are other factors involved in DN development, including obesity, metabolic syndrome, insulin resistance, alcohol consumption, platelet activation and increased aggregability, low vitamin D, subclinical inflammation $(25,26)$, a paraneoplastic syndrome in different cancers (27-29), associated chemotherapy treatment (30), genetic factors (31), and increased oxidative stress $(32,33)$.

\section{DN classification and diagnosis}

The primary clinical forms of DN fall into three broad categories considering pathophysiology and anatomy (31): i) Sensory DN with the following types: Acute hyperglycemic neuropathy and chronic sensory-motor neuropathy; ii) focal or multifocal DN that include mononeuropathies (median, ulnar, radial nerve, and cranial nerves), radiculopathies, plexopathies, amyotrophy; iii) autonomic neuropathies that include: Cardiovascular autonomic neuropathy manifesting as reduction of heart rate variation, tachycardia during resting intervals, postural hypotension as well as sudden cardiac death (especially malignant arrhythmias); gastrointestinal autonomic neuropathy such as diabetic gastroparesis, colonic hypomotility or hypermotility, and diabetic enteropathy; genitourinary autonomic neuropathy meaning erectile, bladder and sudomotor dysfunction.

The ADA advises physicians to use at least two semi-quantitative tests to diagnose DN (8). The tests used to evaluate the functioning of thin nerve fibres include the temperature perception test, and the pinprick pain perception test, whereas those that assess long nerve fibres function are the vibration perception test, the monofilament touch perception test, and the evaluation of ankle reflexes (8). The unity of at least two tests 
is necessary to increase the specificity of DN diagnosis (8). Confirmation of DN diagnosis requires complex and rarely performed examinations such as nerve conduction tests that demonstrate the slowing of nerve conduction as a consequence of segmental demyelination of the axons (34).

Autonomic DN includes a group of diseases in which the nerve fibres belonging to the sympathetic and the parasympathetic nervous system are damaged, especially non-myelinated vegetative filaments (31). Autonomic DN can affect the cardiac, digestive, urinary and genital systems, being often undiagnosed, although it can occur within the first years after the diagnosis of DM (35). Cardiac autonomic neuropathy correlates with increased cardiac mortality (36). Its clinical manifestations include resting sinus tachycardia, silent myocardial ischemia, diminished tolerance to physical effort, orthostatic hypotension, syncope and intra-operative cardiac instability (36). The prevalence of autonomic cardiac neuropathy is approximately $30 \%$ in subjects with type $1 \mathrm{DM}$ after 20 years of disease, and 60\% in subjects with type 2 DM after 15 years of disease progression (8). The presence of autonomic cardiac neuropathy increases cardiovascular risk, being involved either directly as a cause of cardiovascular diseases, or indirectly as an aggravating factor of pre-existing pathologies. Part of this risk is contributed to the presence of silent myocardial infarction that occurs with a much higher frequency in DM individuals (37). Autonomic cardiac neuropathy also involves significant damage to the parasympathetic system; this accentuates the predominance of the sympathetic nervous system, which may produce a chronic increase in blood pressure and eventually, hypertension (38). Nevertheless, DN does not spare the sympathetic system; it can be affected by the appearance of postural hypotension $(35,36)$.

Sinus tachycardia occurs as a result of an imbalance between the sympathetic and parasympathetic nervous systems over the sinoatrial node (37), different from atrial fibrillation (39). Cardiac neuropathy is also associated with impaired diastolic filling (38). In the initial stages, sinus tachycardia with a heart rate $>90$ bpm occurs, followed by sinus tachycardia with a fixed frequency. For diagnosis tachycardia, clinicians use bedside tests developed from Ewing's methods in 1970. It includes the analysis of R-R interval changes on the electrocardiogram during deep breathing, standing, or Valsalva manoeuvre (increased intrathoracic pressure) (38). Additionally, head-up-tilt-table test or imaging techniques such as positron emission tomography (PET) or $\left[{ }^{123} \mathrm{I}\right]$ meta-iodobenzylguanidine (MIBG) can be used in dedicated centres (8). Autonomic DN can affect the gastrointestinal tract $(40,41)$. Impairment of the sympathetic and parasympathetic nervous system innervating the digestive tract, with the predominant loss of inhibitory neurons and the imbalance between neuropeptides, can lead to diarrhoea or constipation, gastroparesis, disorders of oesophageal motility, faecal incontinence or biliary tract dyskinesia $(40,41)$. A series of tests are performed to exclude other organic causes, most frequently esophagogastroduodenoscopy, colonoscopy, or a barium study of the stomach. The gold standard for diagnosing gastroparesis is scintigraphy of digestible solids with the measurement of gastric emptying (8).

At the urinary level, the clinical manifestation of $\mathrm{DN}$ is bladder dysfunction (42). The sensation of filling the bladder is no longer perceived, so there is urinary retention, dysuria, nocturia, and incomplete emptying. This can be evaluated by echography after voiding. In later stages of the disease, control over the smooth sphincter is lost, and thus urinary incontinence appears (43). The presence of bladder urine stasis predisposes these patients to severe urinary infections (43). In men suffering from DM, sexual dysfunction is three times more prevalent than in individuals with normal glucose tolerance (44). Sexual dysfunction, especially erectile dysfunction, is a disability to obtain or maintain a normal erection for sexual intercourse $(44,45)$. The 'International Index of Erectile Function' study is a validated diagnostic tool (46). The prevalence of erectile dysfunction seems to be very high; in a study, $67 \%$ of the evaluated subjects with DM were diagnosed with erectile dysfunction (44). A urologic examination is required for these conditions. In women with DM, sexual dysfunction is manifested by decreased libido and dyspareunia and should be evaluated by the gynaecologist (47).

\section{Current treatment options}

\section{Pathogenesis-oriented treatment}

Glycaemic control. Glycaemic control is particularly important in the primary and secondary prevention of distal symmetrical diabetic polyneuropathy in patients with type $1 \mathrm{DM}$ (12). The DCCT study included 1,400 subjects with type $1 \mathrm{DM}$, which were randomly divided into an intensive HbA1c target group $(<6 \%)$, and a conventional one (12). After a follow-up period of around 6.5 years, HbAlc was $7.4 \%$ in the intensive group and $9.1 \%$ in the conventional group (12). The prevalence of confirmed DN markedly increased in the conventional treatment participants (from 5 to $17 \% ; \mathrm{P}<0.001$ ), and only slightly among the intensive treatment group participants (from 7 to 9\%). Adjusting for the presence of confirmed DN at baseline, the risk reduction for incident $\mathrm{DN}$ with intensive glucose control during DCCT was 64\% (95\% CI: 45-76, P<0.01). Subjects included in the DCCT study were then followed up to observe the long-term effects of glycaemic control on the incidence of microvascular and macrovascular DM complications. Patients in the DCCT study who were included in the conventional control arm were switched at the start of the 'Epidemiology of Diabetes Interventions and Complications' (EDIC) study to an intensive treatment arm. It was observed that the $\mathrm{HbAlc}$ difference between intensive and conventional glycemia treatment groups in the DCCT study was rapidly reduced; by the fifth year of EDIC follow-up, there was no statistically significant A1c division (7.9\% vs. 8.2\%) (48). Prevalence of DN was raised during EDIC follow-up in the two groups. Despite no measurable difference in glucose control, a 30\% risk decrease in evolving DN was observed in patients with prior intensive glucose, confirming that early benefits in achieving glucose control are persistent over time (48). The EDIC/DCCT studies demonstrated that good glycaemic management can reduce DN occurrence and progression in subjects with type $1 \mathrm{DM}$ and that initial intensive glucose control maintains its benefits for a long time $(47,48)$.

On the other hand, glycaemic control seemed not to influence the frequency of DN in type 2 DM subjects. Briefly, in the UKPDS study (performed on 3,867 types 2 DM patients with a similar methodology to that of the DCCT study) 
Table I. Recommendations of the American Neurology Association (AAN) for the treatment of symptoms of painful symmetrical polyneuropathy.

\begin{tabular}{llll}
\hline Level of recommendation & \multicolumn{1}{c}{ Drug } & \multicolumn{1}{c}{ Effective dose } & \multicolumn{1}{c}{ Not recommended drugs } \\
\hline A & Pregabalin & $300-600 \mathrm{mg} / \mathrm{day}$ & Oxcarbazepine \\
$\mathrm{B}$ & Gabapentin & $500-1,200 \mathrm{mg} / \mathrm{day}$ & Lamotrigine \\
& Duloxetine & $60-120 \mathrm{mg} / \mathrm{day}$ & Clonidine \\
& Venlafaxine & $75-225 \mathrm{mg} / \mathrm{day}$ & Laser therapy with low intensity \\
& Sodium valproate & $500-1,200 \mathrm{mg} /$ day & \\
& Amitriptyline & $25-100 \mathrm{mg} / \mathrm{day}$ & \\
& Tramadol & $210 \mathrm{mg} /$ day & \\
& Capsaicin & $0.075 \%$ topic use 4 times a day & \\
\hline
\end{tabular}

patients were divided into the intensive and the conventional glucose control (49). At 10 years, no significant difference was observed regarding the prevalence of distal symmetrical DN and autonomic cardiovascular neuropathy between the two groups, in the intensive treatment group the average HbAlc was $7 \%$ while in the conventional treatment group the average HbAlc was $7.9 \%, \mathrm{P}<0.01$ (49). The treatment used for diabetic control, and not HbAlc decrease per se, could have a role in neuropathy prevention. This explains the reason for the population from BARI 2D, following treatment with insulin sensitizers, having reduced chronic distal polyneuropathy incidence (19). A meta-analysis, conducted in 2011, analyzed six trials performed on 21,702 type 2 DM individuals, showing no effect of intensive glucose control on DN development or progression (50). Similarly, in another meta-analysis, including 6,669 type 2 DM patients from four studies, enhanced glucose control non-significantly reduced the incidence of clinical neuropathy (15).

Aldose-reductase inhibitors. In patients with DM, glucose metabolism via the polyols pathway begins with the transformation of glucose into sorbitol, a reaction catalyzed by aldose-reductase (51). Sorbitol exerts a robust osmotic effect that alters $\mathrm{Na}^{+} / \mathrm{K}^{+}$-ATPase in neurons. Aldose-reductase inhibitors act by decreasing the cellular levels of sorbitol (51). Aldose-reductase inhibitors were previously reported to improve symptoms and nerve conduction in the motor nerves in patients with distal symmetrical DN (52). However, a meta-analysis, including 32 trials, demonstrated that aldose-reductase inhibitors are no more effective than placebo in improving the symptoms of DN and nerve conduction; thus the medication is not included in the ADA guidelines $(8,53)$. By contrast, another meta-analysis $(n=10$ trials) showed that aldose-reductase inhibitors ameliorated automatic cardiac neuropathy, mostly mild or asymptomatic cases (54).

a-lipoic acid. $\alpha$-lipoic acid (ALA) may reduce oxidative stress, which is a central component in the etiopathogenesis of DN (55). Hyperglycaemia enhances the generation of reactive oxygen species (ROS) and depletes endogenous antioxidant mechanisms (55). ROS are crucial contributors to neuronal apoptosis, thus predisposing to DN progression (55). Previous studies in rodents have shown that ALA decreased lipid peroxidation in a dose-dependent manner (56). ALA has been used in DN, since nerve fibres, especially in the myelin sheath, exhibit a large amount of lipids. The main action of ALA is a 'scavenger effect' on lipophilic-free radicals (55). A series of experimental studies have shown that ALA may improve the local blood flow and increase the speed of nerve conduction in peripheral nerves (57).

In the 'Alpha-Lipoic Acid in Diabetic Neuropathy' (ALADIN) study, ALA was administered intravenously for three weeks in subjects with symptomatic DN at a dose of 600 or 1,200 mg daily; this treatment reduced the symptoms of DN without significant adverse effects (58). Similarly, in the 'Oral Pilot' (ORPIL) study, ALA, administered orally at a dose of $600 \mathrm{mg}$ for three weeks, decreased DN symptoms, including pain, burning sensation, paraesthesia and numbness (59). The 'Symptomatic Diabetic Neuropathy' (SYDNEY) study demonstrated that, in addition to DN symptoms, nerve conduction was also improved by ALA, administered intravenously for five days in 14 perfusions (60). In the SYDNEY 2 study, the oral $600 \mathrm{mg}$ dose of ALA was proven the most effective dose (among 600, 1,200 and 1,800 $\mathrm{mg}$ ) in reducing symptoms and with the fewest side effects during a follow-up of 5 weeks (61). A meta-analysis (4 studies) showed that ALA administered both orally and intravenously can reduce the symptoms of DN as assessed by the 'Total Symptom Score' (TSS), i.e., a scoring system for neuropathic symptoms (burning, pain, numbness and paresthesia) (59). However, clinically relevant reductions in TSS (i.e., $>30 \%$ ) were only observed with intravenously administered ALA at $600 \mathrm{mg} /$ day for 3 weeks, but not with orally administered ALA at a dose of $>600 \mathrm{mg}$ /day for 3-5 weeks (62). Another meta-analysis (15 trials) revealed that the intravenous administration of ALA at a dose of 300-600 mg/day for 2-4 weeks significantly elevated the nerve conduction velocity and positive neuropathic symptoms (63).

Benfotiamine. Benfotiamine is a synthetic derivative form of vitamin B1 that is highly soluble in lipids. Thiamine is recognized as a cofactor of an enzyme known as transketolase, which is part of the fructose- 6 phosphate metabolism and glyceraldehyde-3-phosphate metabolism by pentose-pathway, leading to their conversion to pentose-5 phosphates and other sugars (64). In DM, a thiamine deficiency is frequently present, partially attributed to an increased renal clearance of this vitamin; serum thiamine levels were $75 \%$ lower in patients with DM than in healthy subjects (65). By administering 
Table II. Recommendations of the American Diabetes Association (ADA) regarding therapeutic options for symptomatic diabetic neuropathy.

\begin{tabular}{|c|c|c|c|c|}
\hline $\begin{array}{l}\text { Level of } \\
\text { recommendation }\end{array}$ & Therapeutic class & $\begin{array}{l}\text { Active } \\
\text { substance }\end{array}$ & Effective dosage & Observations \\
\hline \multirow[t]{3}{*}{ A } & Anticonvulsant & Pregabalin & $300-600 \mathrm{mg} /$ day & FDA approved \\
\hline & & & & $\begin{array}{l}\text { Side effects: Ataxia, blurred vision, constipation, } \\
\text { diplopia, dizziness, drowsiness, fatigue }\end{array}$ \\
\hline & $\begin{array}{l}\text { Serotonin reuptake } \\
\text { inhibitors }\end{array}$ & Duloxetine & $60-120 \mathrm{mg} /$ day & FDA approved \\
\hline \multirow[t]{2}{*}{ B } & Anticonvulsant & Gabapentin & $900-3,600 \mathrm{mg} /$ day & More important side effects than pregabalin \\
\hline & $\begin{array}{l}\text { Tricyclic } \\
\text { antidepressant }\end{array}$ & Amitriptyline & $25-100 \mathrm{mg} /$ day & $\begin{array}{l}\text { Important side effects: Cardiotoxicity, } \\
\text { hepatotoxicity, suicidal ideation, risk of } \\
\text { fractures }\end{array}$ \\
\hline \multirow[t]{4}{*}{ E } & Opioids & Tramadol & $210 \mathrm{mg} /$ day & $\begin{array}{l}\text { Significant side effects: Drowsiness, nausea, } \\
\text { vomiting, constipation, arrhythmias, shortness } \\
\text { of breath, seizures, addiction }\end{array}$ \\
\hline & & Tapentadol & $\begin{array}{l}\text { Immediate release: } \\
700 \mathrm{mg} / \text { day, day } 1 \\
\text { then } 60 \mathrm{mg} / \text { day }\end{array}$ & $\begin{array}{l}\text { Important side effects: Drowsiness, nausea, } \\
\text { vomiting, constipation, arrhythmias, shortness } \\
\text { of breath, seizures, addiction }\end{array}$ \\
\hline & & & Prolonged release: & \\
\hline & & & $50 \mathrm{mg}$ twice a day & \\
\hline
\end{tabular}
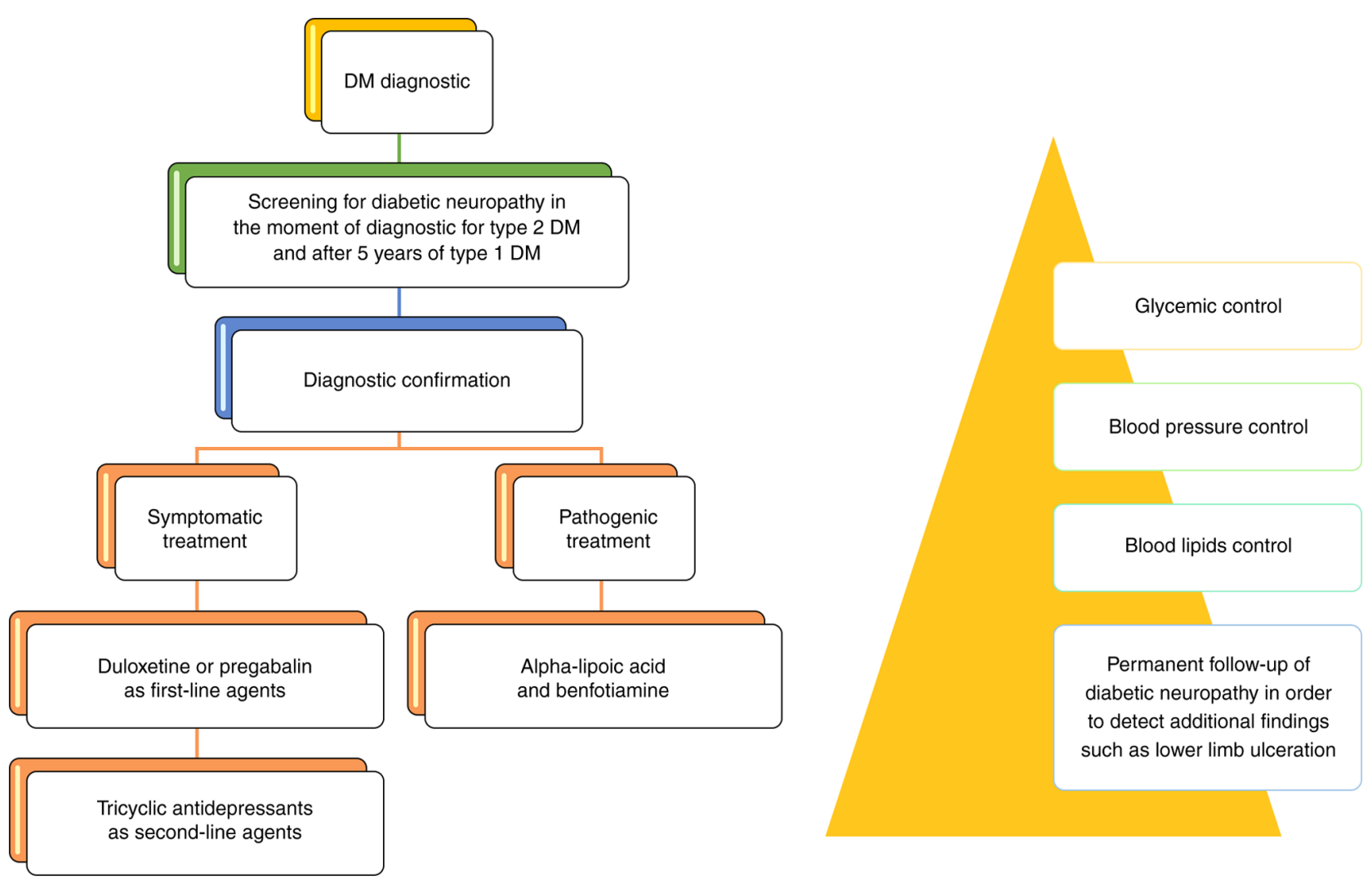

Figure 1. Diabetic mellitus neuropathy management. The left part of the figure shows an algorithm for drug treatment options, and the right side indicates the pathogenesis-oriented strategy.

benfotiamine, fundamental pathogenetic pathways involved in the onset of DN are inhibited (i.e., the hexosamine and the diacylglycerol-protein kinase $\mathrm{C}$ pathways), thus resulting in the reduced formation of advanced glycosylation products (66). In animal studies, benfotiamine given to rodents reduced inflammatory and neuropathic nociception (66). Furthermore, 
in rodents with streptozotocin-induced DM, thiamine, and benfotiamine significantly decreased advanced glycosylation end products levels (67).

In patients with DM, benfotiamine (orally administered at a dose of $100 \mathrm{mg}$, four times a day, for three weeks) was reported to reduce the symptoms of neuropathy (68). In another study, benfotiamine was given in combination with vitamin B6 and B12 at two different doses (i.e., high: $320 \mathrm{mg} /$ day and medium: $150 \mathrm{mg} /$ day), as well as monotherapy (150 mg/day) for 6 weeks in $36 \mathrm{DM}$ patients with DN (69). Both symptoms and semi-quantitative tests were improved in all the groups with the best results being obtained in the patients receiving the highest dose of benfotiamine (69). Other findings have shown that benfotiamine, in combination with pyridoxine, not only reduces DN symptoms but also increases the speed of nerve conduction (70). Overall, benfotiamine significantly improves the symptoms of DN in DM patients, the benefit being greater with a higher amount and longer duration of treatment (71).

Symptomatic treatment. Symptomatic treatment aims to significantly reduce self-reported pain in the lower limbs by $30-50 \%$ and thus improve the quality of life (8). A series of symptomatic medications are included in the guidelines by the 'American Academy of Neurology' (AAN) (72) (Table I) or the 'European Federation of Neurological Societies' (EFNS) (73). Beneficial results have been obtained with tricyclic antidepressants (for example amitriptyline), serotonin reuptake inhibitors, such as duloxetine $(74,75)$ or opioids $(76)$ or pregabalin (77) and gabapentin (78). The ADA recommends duloxetine as a first-line treatment for the symptoms of painful DN, the other alternative being pregabalin (Table II) (8). Previous findings demonstrated the efficacy of duloxetine for the treatment of pain in patients with DN. The usually administered dose is 60 or $120 \mathrm{mg} /$ day (74). Duloxetine at a dose of $60 \mathrm{mg} /$ day is safe and effective in the treatment of $\mathrm{DN}$, but it should be elided in patients with liver disease and/or advanced chronic kidney disease. Administration of $>60 \mathrm{mg} /$ day is not indicated since efficacy is not significantly higher, and the side effects are greater (74). Of note, duloxetine is cost-effective compared to other drugs used in DN treatment (75). A meta-analysis of 23 studies confirmed the efficacy of duloxetine in the symptomatic treatment of DN (79).

Furthermore, tramadol was more effective than placebo in treating pain in patients with DN given at a dose of $200 \mathrm{mg} / \mathrm{day}$, also improving patients' quality of life (80). Overall, tramadol, in combination with paracetamol, is useful in the symptomatic therapy of DN by reducing the severity of pain, improving sleep and quality of life (81).

\section{Experimental treatment}

As technology advances, novel biomarkers and diagnostic procedures for DN are implemented $(82,83)$, leading to innovative therapies.

Experimental drug treatment for DN includes vixotirgine, a voltage-gated sodium-channel agonist (84); trazodone/pregabalin combination, a combination between a second-generation antidepressant with sedative activity and an anticonvulsant that has been effective in reducing symptoms (85); olodanrigan, an angiotensin 2 type 2 receptor antagonist (86); inhibitors of enkephalinases that increase the concentrations of enkephalin substances known for their natural analgesic proprieties (87); and vitamin $\mathrm{D}$ which can improve mood and decrease pain severity as shown in small trials (88).

Capsaicin can be used as topical treatment based on the local tissue reduction in $\mathrm{P}$-substance responsible for pain sensation $(89,90)$ but is not generally recommended because it can determine a reversible loss of small epidermal fibres (8).

\section{Suggestions for a therapeutic approach}

DN treatment needs a multitarget approach, as depicted in Fig. 1. In our opinion, no treatment is effective if metabolic control is not achieved. Regulation of glucose, blood pressure and lipids are key components of a reliable approach for reducing the progression of DN since nerve fibres are highly sensitive to hyperglycaemia, hypertension and hyperlipidaemia by the generation of excessive free radicals in the nervous tissue or plasma (8). Therefore, patients may benefit from both symptomatic and pathogenic treatment. The quality of life is also very important, and symptomatic treatment can improve it by the use of drugs such as duloxetine, pregabalin or gabapentin $(8,71)$. Some guidelines do not refer to pathogenetic therapy, such as ALA or benfotiamine. However, proof exists that, especially ALA administered intravenously is effective in reducing neuropathic pain and improving nerve conduction (58). Overall, pathogenic treatment can, not only promote specific nerve function, but also improve the patient's symptoms as a consequence of neuroprotection against oxidative stress and advanced glycosylation end products $(55,56,67,68)$. In clinical practice, ALA is usually administered intravenously for 10-14 days, at a dose of $600 \mathrm{mg} / \mathrm{day}$, followed by a long term oral administration of a combination of ALA (600 $\mathrm{mg} / \mathrm{day})$ and benfotiamine $300 \mathrm{mg} /$ day.

\section{Conclusions}

Timely diagnosis of DN is required to avoid several complications, including lower limb amputations and cardiac arrhythmias. Glucose, blood pressure and lipids control are of high importance in DN therapy. Symptomatic treatment improves the quality of life of patients. Of note, pathogenetic therapeutic agents such as ALA and benfotiamine should not be ignored as they have shown positive results in clinical practice.

\section{Acknowledgements}

Fig. 1 was made by CMV in PowerPoint, using only information from clinical practice.

\section{Funding}

No funding was received.

\section{Availability of data and materials}

Not applicable. 


\section{Authors' contributions}

AB, APS, MP, CMV conceived the structure of the review. ARP, NK, RAS and CD collected the data and performed the literature search. NP, CMV, MS, and RAS revised the study for intellectual content. All authors were involved in writing the manuscript. All authors read and approved the final manuscript.

\section{Ethics approval and consent to participate}

Not applicable.

\section{Patient consent for publication}

Not applicable.

\section{Competing interests}

NK has given talks, attended conferences and participated in trials sponsored by Astra Zeneca, Bausch Health, Boehringer Ingelheim, Elpen, Mylan, Novo Nordisk, Sanofi and Servier. APS is currently Vice President of the Romanian National Diabetes Committee and has given talks, attended conferences and participated in advisory boards sponsored by Astra Zeneca, Novo Nordisk, Sanofi, Medtronic, Roche, Lilly, Merck, Amgen and Coca-Cola. NP has been an advisory board member of Astra-Zeneca, Boehringer Ingelheim, MSD, Novo Nordisk, Pfizer, Takeda and TrigoCare International; has participated in sponsored studies by Astra-Zeneca, Eli-Lilly, GSK, MSD, Novo Nordisk, Novartis and Sanofi-Aventis; has received honoraria as a speaker for Astra-Zeneca, Boehringer Ingelheim, Eli-Lilly, Elpen, MSD, Mylan, Novo Nordisk, Pfizer, Sanofi-Aventis and Vianex; and attended conferences sponsored by TrigoCare International, Eli-Lilly, Galenica, Novo Nordisk, Pfizer and Sanofi-Aventis. RAS has attended conferences sponsored by Novo Nordisk, Worwag Pharma, Eli-Lilly. The remaining authors have no competing interests to declare.

\section{References}

1. Bansal V, Kalita J and Misra UK: Diabetic neuropathy. Postgrad Med J 82: 95-100, 2006.

2. Kaur S, Pandhi P and Dutta P: Painful diabetic neuropathy: An update. Ann Neurosci 18: 168-175, 2011.

3. Román-Pintos LM, Villegas-Rivera G, Rodríguez-Carrizalez AD, Miranda-Díaz AG and Cardona-Muñoz EG: Diabetic polyneuropathy in type 2 diabetes mellitus: Inflammation, oxidative stress, and mitochondrial function. J Diabetes Res 2016: 3425617, 2016.

4. Dyck PJ, Kratz KM, Karnes JL, Litchy WJ, Klein R, Pach JM, Wilson DM, O'Brien PC, Melton LJ III and Service FJ: The prevalence by staged severity of various types of diabetic neuropathy, retinopathy, and nephropathy in a population-based cohort: The rochester diabetic neuropathy study. Neurology 43: 817-824, 1993

5. Young MJ, Boulton AJ, MacLeod AF, Williams DR and Sonksen PH: A multicentre study of the prevalence of diabetic peripheral neuropathy in the United Kingdom hospital clinic population. Diabetologia 36: 150-154, 1993.

6. Jaiswal M, Lauer A, Martin CL, Bell RA, Divers J, Dabelea D, Pettitt DJ, Saydah S, Pihoker C, Standiford DA, et al: SEARCH for Diabetes in Youth Study Group: Peripheral neuropathy in adolescents and young adults with type 1 and type 2 diabetes from the SEARCH for Diabetes in Youth follow-up cohort: A pilot study. Diabetes Care 36: 3903-3908, 2013.
7. Veresiu AI, Bondor CI, Florea B, Vinik EJ, Vinik AI and Gâvan NA: Detection of undisclosed neuropathy and assessment of its impact on quality of life: A survey in 25,000 Romanian patients with diabetes. J Diabetes Complications 29: 644-649, 2015.

8. Pop-Busui R, Boulton AJ, Feldman EL, Bril V, Freeman R, Malik RA, Sosenko JM and Ziegler D: Diabetic neuropathy: A position statement by the American diabetes association. Diabetes Care 40: 136-154, 2017.

9. Vinik AI: Advances in diabetes for the millennium: New treatments for diabetic neuropathies. MedGenMed 6 (3 Suppl): S13, 2004.

10. Rathmann W, Ziegler D, Jahnke M, Haastert B and Gries FA: Mortality in diabetic patients with cardiovascular autonomic neuropathy. Diabet Med 10: 820-824, 1993.

11. Bansal D, Gudala K, Muthyala H, Esam HP, Nayakallu R and Bhansali A: Prevalence and risk factors of development of peripheral diabetic neuropathy in type 2 diabetes mellitus in a tertiary care setting. J Diabetes Investig 5: 714-721, 2014.

12. Diabetes Control and Complications Trial Research Group, Nathan DM, Genuth S, Lachin J, Cleary P, Crofford O, Davis M, Rand L and Siebert C: The effect of intensive treatment of diabetes on the development and progression of long-term complications in insulin-dependent diabetes mellitus. N Engl J Med 329: 977-986, 1993.

13. Klein R, Klein BE and Moss SE: Relation of glycemic control to diabetic microvascular complications in diabetes mellitus. Ann Intern Med 124: 90-96, 1996.

14. Tesfaye S, Chaturvedi N, Eaton SE, Ward JD, Manes C, Ionescu-Tirgoviste C, Witte DR and Fuller JH; EURODIAB Prospective Complications Study Group: Vascular risk factors and diabetic neuropathy. N Engl J Med 352: 341-350, 2005.

15. Action to Control Cardiovascular Risk in Diabetes Study Group, Gerstein HC, Miller ME, Byington RP, Goff DC Jr, Bigger JT, Buse JB, Cushman WC, Genuth S, Ismail-Beigi F, et al: Effects of intensive glucose lowering in type 2 diabetes. N Engl J Med 358: 2545-2559, 2008.

16. Callaghan BC, Little AA, Feldman EL and Hughes RA: Enhanced glucose control for preventing and treating diabetic neuropathy. Cochrane Database Syst Rev 6: CD007543, 2012.

17. Ismail-Beigi $\mathrm{F}$, Craven $\mathrm{T}$, Banerji MA, Basile J, Calles J, Cohen RM, Cuddihy R, Cushman WC, Genuth S, Grimm RH Jr, et al: Effect of intensive treatment of hyperglycaemia on microvascular outcomes in type 2 diabetes: An analysis of the ACCORD randomized trial. Lancet 376: 419-430, 2010.

18. Gaede P, Vedel P, Larsen N, Jensen GV, Parving HH and Pedersen O: Multifactorial intervention and cardiovascular disease in patients with type 2 diabetes. N Engl J Med 348: 383-393, 2003.

19. BARI 2D Study Group, Frye RL, August P, Brooks MM, Hardison RM, Kelsey SF, MacGregor JM, Orchard TJ, Chaitman BR, Genuth SM, et al: A randomized trial of therapies for type 2 diabetes and coronary artery disease. N Engl J Med 360: 2503-2515, 2009.

20. Ardeleanu V, Toma A, Pafili K, Papanas N, Motofei I, Diaconu CC, Rizzo M and Stoian AP: Current pharmacological treatment of painful diabetic neuropathy: A narrative review. Medicina (Kaunas) 56: 25, 2020.

21. Gregory JA, Jolivalt CG, Goor J, Mizisin AP and Calcutt NA: Hypertension-induced peripheral neuropathy and the combined effects of hypertension and diabetes on nerve structure and function in rats. Acta Neuropathol 124: 561-573, 2012.

22. Elliott J, Tesfaye S, Chaturvedi N, Gandhi RA, Stevens LK, Emery C and Fuller JH: EURODIAB Prospective Complications Study Group: Large-fiber dysfunction in diabetic peripheral neuropathy is predicted by cardiovascular risk factors. Diabetes Care 32: 1896-1900, 2009.

23. Perez-Matos MC, Morales-Alvarez MC and Mendivil CO: Lipids: A suitable therapeutic target in diabetic neuropathy? J Diabetes Res 2017: 6943851, 2017.

24. Clair C, Cohen MJ, Eichler F, Selby KJ and Rigotti NA: The effect of cigarette smoking on diabetic peripheral neuropathy: A systematic review and meta-analysis. J Gen Intern Med 30: 1193-1203, 2015

25. Papanas $\mathrm{N}$ and Ziegler D: Risk factors and comorbidities in diabetic neuropathy: An update 2015. Rev Diabet Stud 12: 48-62, 2015.

26. Tesfaye S, Stevens LK, Stephenson JM, Fuller JH, Plater M, Ionescu-Tirgoviste C, Nuber A, Pozza G and Ward JD: Prevalence of diabetic peripheral neuropathy and its relation to glycaemic control and potential risk factors: The EURODIAB IDDM complications study. Diabetologia 39: 1377-1384, 1996. 
27. Mazilu L, Stanculeanu DL, Gheorghe AD, Suceveanu AP, Parepa IR, Stoian Pantea A and Suceveanu AI: Clinical impact of association between diabetes and lung cancer. Rev Chim 70: $1149-1151,2019$

28. Suceveanu AI, Suceveanu AP, Gheorghe AD and Mazilu L: Diabetes and cancer-is there a link? In: Diabetes and its complications, Gaber AR (ed). InTech, pp119-137, 2017.

29. Suceveanu AI, Mazilu L, Nitipir C, Stoian AP, Parepa I, Voinea C and Suceveanu AP: Diabetes mellitus raise the risk for interval colorectal cancer and advanced adenomas. Rev Chim 70: 1808-1811, 2019.

30. Mazilu L, Stanculeanu DL, Gheorghe AD, Voinea F, Suceveanu AP, Pituru S, Diaconu CC, Parepa IR, Pantea Stoian A, Pop CS and Suceveanu AI: Incidence of chemotherapy induced peripheral neuropathy in cancer patients in clinical practice. Farmacia 66: 904-908, 2018

31. Boulton AJ, Vinik AI, Arezzo JC, Bril V, Feldman EL, Freeman R, Malik RA, Maser RE, Sosenko JM and Ziegler D; American Diabetes Association: Diabetic neuropathies: A statement by the American Diabetes Association. Diabetes Care 28 956-962, 2005

32. Gheorghe G, Stoian AP, Gaman M, Socea B, Neagu TP, Stanescu AMA, Bratu OG, Mischianu DLD, Suceveanu AI and Diaconu CC: The benefits and risks of antioxidant treatment in liver diseases. Rev Chim 70: 651-655, 2019.

33. Stoian AP, Mitrofan G, Colceag F, Suceveanu AI, Hainarosie R Pituru S, Diaconu CC, Timofte D, Nitipir C, Poiana C and Serafinceanu C: Oxidative stress in diabetes. A model of complex thinking applied in medicine. Rev Chim 69: 2515-2519, 2018.

34. Bromberg MB: An electrodiagnostic approach to the evaluation of peripheral neuropathies. Phys Med Rehabil Clin N Am 24 $153-168,2013$

35. Verrotti A, Prezioso G, Scattoni R and Chiarelli F: Autonomic neuropathy in diabetes mellitus. Front Endocrinol (Lausanne) 5 : $205,2014$.

36. Serhiyenko VA and Serhiyenko AA: Cardiac autonomic neuropathy: Risk factors, diagnosis and treatment. World J Diabetes 9: $1-24,2018$.

37. Vinik AI, Erbas T and Casellini CM: Diabetic cardiac autonomic neuropathy, inflammation and cardiovascular disease. J Diabetes Investig 4: 4-18, 2013.

38. Vinik AI and Ziegler D: Diabetic cardiovascular autonomic neuropathy. Circulation 115: 387-397, 2007.

39. Gaman MA, Dobrica EC, Pascu EG, Cozma MA, Epingeac ME, Gaman AM, Pantea Stoian AM, Bratu OG and Diaconu CC: Cardio metabolic risk factors for atrial fibrillation in type 2 diabetes mellitus: Focus on hypertension, metabolic syndrome and obesity. J Mind Med Sci 6: 157-161, 2019.

40. Yarandi SS and Srinivasan S: Diabetic gastrointestinal motility disorders and the role of enteric nervous system: Current status and future directions. Neurogastroenterol Motil 26: 611-624, 2014.

41. Parkman HP, Yates K, Hasler WL, Nguyen L, Pasricha PJ, Snape WJ, Farrugia G, Koch KL, Calles J, Abell TL, et al Similarities and differences between diabetic and idiopathic gastroparesis. Clin Gastroenterol Hepatol 9: 1056-1064, 2011.

42. Yuan Z, Tang Z, He C and Tang W: Diabetic cystopathy: A review. J Diabetes 7: 442-447, 2015.

43. Zaha DC, Kiss R, Hegedûs C, Gesztelyi R, Bombicz M, Muresan M, Pallag A, Zrinyi M, Pall D, Vesa CM and Micle O Recent advances in investigation, prevention, and management of healthcare-associated infections (HAIs): Resistant multidrug strain colonization and its risk factors in an intensive care unit of a university hospital. Biomed Res Int 2019: 2510875, 2019.

44. Maiorino MI, Bellastella G and Esposito K: Diabetes and sexual dysfunction: Current perspectives. Diabetes Metab Syndr Obes 7: 95-105, 2014.

45. Sáenz de Tejada I, Angulo J, Cellek S, González-Cadavid N, Heaton J, Pickard R and Simonsen U: Pathophysiology of erectile dysfunction. J Sex Med 2: 26-39, 2005.

46. Rhoden EL, Telöken C, Sogari PR and Vargas Souto CA: The use of the simplified international index of erectile function (IIEF-5) as a diagnostic tool to study the prevalence of erectile dysfunction. Int J Impot Res 14: 245-250, 2002

47. Enzlin P, Rosen R, Wiegel M, Brown J, Wessells H, Gatcomb P, Rutledge B, Chan KL and Cleary PA; DCCT/EDIC Research Group: Sexual dysfunction in women with type 1 diabetes: Long-term findings from the DCCT/EDIC study cohort. Diabetes Care 32: 780-785, 2009
48. Pop-Busui R, Herman WH, Feldman EL, Low PA, Martin CL, Cleary PA, Waberski BH, Lachin JM and Albers JW; DCCT/EDIC Research Group: DCCT and EDIC studies in type 1 diabetes: Lessons for diabetic neuropathy regarding metabolic memory and natural history. Curr Diab Rep 10: 276-282, 2010.

49. Intensive blood-glucose control with sulphonylureas or insulin compared with conventional treatment and risk of complications in patients with type 2 diabetes (UKPDS 33). UK prospective diabetes study (UKPDS) group. Lancet 352: 837-853, 1998.

50. Boussageon R, Bejan-Angoulvant T, Saadatian-Elahi M, Lafont S, Bergeonneau C, Kassaï B, Erpeldinger S, Wright JM, Gueyffier F and Cornu C: Effect of intensive glucose lowering treatment on all cause mortality, cardiovascular death, and microvascular events in type 2 diabetes: Meta-analysis of randomized controlled trials. BMJ 343: d4169, 2011

51. Ramirez MA and Borja NL: Epalrestat: An aldose reductase inhibitor for the treatment of diabetic neuropathy. Pharmacotherapy 28: 646-655, 2008.

52. Sharma SR and Sharma N: Epalrestat, an aldose reductase inhibitor, in diabetic neuropathy: An Indian perspective. Ann Indian Acad Neurol 11: 231-235, 2008

53. Chalk C, Benstead TJ and Moore F: Aldose reductase inhibitors for the treatment of diabetic polyneuropathy. Cochrane Database Syst Rev: CD004572, 2007.

54. Hu X, Li S, Yang G, Liu H, Boden G and Li L: Efficacy and safety of aldose reductase inhibitor for the treatment of diabetic cardiovascular autonomic neuropathy: Systematic review and meta-analysis. PLoS One 9: e87096, 2014.

55. Vallianou N, Evangelopoulos A and Koutalas P: Alpha-lipoic acid and diabetic neuropathy. Rev Diabet Stud 6: 230-236, 2009.

56. Nickander KK, McPhee BR, Low PA and Tritschler H: Alpha-lipoic acid: Antioxidant potency against lipid peroxidation of neural tissues in vitro and implications for diabetic neuropathy. Free Radic Biol Med 21: 631-639, 1996.

57. Nagamatsu M, Nickander KK, Schmelzer JD, Raya A, Wittrock DA, Tritschler H and Low PA: Lipoic acid improves nerve blood flow, reduces oxidative stress, and improves distal nerve conduction in experimental diabetic neuropathy. Diabetes Care 18: 1160-1167, 1995

58. Ziegler D, Hanefeld M, Ruhnau KJ, Meissner HP, Lobisch M, Schütte K and Gries FA: Treatment of symptomatic diabetic peripheral neuropathy with the anti-oxidant alpha-lipoic acid A 3-week multicentre randomized controlled trial (ALADIN Study). Diabetologia 38: 1425-1433, 1995

59. Ruhnau KJ, Meissner HP, Finn JR, Reljanovic M, Lobisch M, Schütte K, Nehrdich D, Tritschler HJ, Mehnert H and Ziegler D: Effects of 3-week oral treatment with the antioxidant thioctic acid (alpha-lipoic acid) in symptomatic diabetic polyneuropathy. Diabet Med 16: 1040-1043, 1999.

60. Ametov AS, Barinov A, Dyck PJ, Hermann R, Kozlova N, Litchy WJ, Low PA, Nehrdich D, Novosadova M, O'Brien PC, et al: The sensory symptoms of diabetic polyneuropathy are improved with alpha-lipoic acid: The SYDNEY trial. Diabetes Care 26: 770-776, 2003

61. Ziegler D, Ametov A, Barinov A, Dyck PJ, Gurieva I, Low PA, Munzel U, Yakhno N, Raz I, Novosadova M, et al: Oral treatment with alpha-lipoic acid improves symptomatic diabetic polyneuropathy: The SYDNEY 2 trial. Diabetes Care 29: 2365-2370, 2006.

62. Mijnhout GS, Kollen BJ, Alkhalaf A, Kleefstra N and Bilo HJ: Alpha lipoic acid for symptomatic peripheral neuropathy in patients with diabetes: A meta-analysis of randomized controlled trials. Int J Endocrinol 2012: 456279, 2012.

63. Han T, Bai J, Liu W and $\mathrm{Hu}$ Y: A systematic review and meta-analysis of $\alpha$-lipoic acid in the treatment of diabetic peripheral neuropathy. Eur J Endocrinol 167: 465-471, 2012.

64. Pácal L, Kuricová K and Kaňková K: Evidence for altered thiamine metabolism in diabetes: Is there a potential to oppose gluco- and lipotoxicity by rational supplementation? World J Diabetes 5: 288-295, 2014.

65. Thornalley PJ, Jahan I and Ng R: Suppression of the accumulation of triosephosphates and increased formation of methylglyoxal in human red blood cells during hyperglycaemia by thiamine in vitro. J Biochem 129: 543-549, 2001.

66. Hammes HP, Du X, Edelstein D, Taguchi T, Matsumura T, Ju Q, Lin J, Bierhaus A, Nawroth P, Hannak D, et al: Benfotiamine blocks three major pathways of hyperglycemic damage and prevents experimental diabetic retinopathy. Nat Med 9: 294-299, 2003. 
67. Sánchez-Ramírez GM, Caram-Salas NL, Rocha-González HI, Vidal-Cantú GC, Medina-Santillán R, Reyes-García G and Granados-Soto V: Benfotiamine relieves inflammatory and neuropathic pain in rats. Eur J Pharmacol 530: 48-53, 2006.

68. Haupt E, Ledermann $H$ and Köpcke W: Benfotiamine in the treatment of diabetic polyneuropathy-a three-week randomized, controlled pilot study (BEDIP study). Int J Clin Pharmacol Ther 43: 71-77, 2005.

69. Winkler G, Pál B, Nagybéganyi E, Ory I, Porochnavec M and Kempler P: Effectiveness of different benfotiamine dosage regimens in the treatment of painful diabetic neuropathy. Arzneimittelforschung 49: 220-224, 1999.

70. Nikolić A, Kacar A, Lavrnić D, Basta I and Apostolski S: The effect of benfothiamine in the therapy of diabetic polyneuropathy. Srp Arh Celok Lek 137: 594-600, 2009.

71. Stracke H, Gaus W, Achenbach U, Federlin K and Bretzel RG: Benfotiamine in diabetic polyneuropathy (BENDIP): Results of a randomised, double blind, placebo-controlled clinical study. Exp Clin Endocrinol Diabetes 116: 600-605, 2008.

72. Bril V, England J, Franklin GM, Backonja M, Cohen J, Del Toro D, Feldman E, Iverson DJ, Perkins B, Russell JW, et al: Evidence-based guideline: Treatment of painful diabetic neuropathy: Report of the American academy of neurology, the American association of neuromuscular and electrodiagnostic medicine, and the American academy of physical medicine and rehabilitation. Neurology 76: 1758-1765, 2011.

73. Attal N, Cruccu G, Baron R, Haanpää M, Hansson P, Jensen TS and Nurmikko T; European Federation of Neurological Societies: EFNS guidelines on the pharmacological treatment of neuropathic pain: 2010 revision. Eur J Neurol 17: 1113-e88, 2010

74. Goldstein DJ, Lu Y, Detke MJ, Lee TC and Iyengar S: Duloxetine vs. placebo in patients with painful diabetic neuropathy. Pain 116 109-118, 2005.

75. Ormseth MJ, Scholz BA and Boomershine CS: Duloxetine in the management of diabetic peripheral neuropathic pain. Patient Prefer Adherence 5: 343-356, 2011.

76. Gilron I, Bailey JM, Tu D, Holden RR, Weaver DF and Houlden RL: Morphine, gabapentin, or their combination for neuropathic pain. N Engl J Med 352: 1324-1334, 2005.

77. Rosenstock J, Tuchman M, LaMoreaux L and Sharma U: Pregabalin for the treatment of painful diabetic peripheral neuropathy: A double-blind, placebo-controlled trial. Pain 110: 628-638, 2004

78. Wiffen P, Collins S, McQuay H, Carroll D, Jadad A and Moore A Anticonvulsant drugs for acute and chronic pain. Cochrane Database Syst Rev: CD001133, 2000.

79. Hossain SM, Hussain SM and Ekram AR: Duloxetine in painful diabetic neuropathy: A systematic review. Clin J Pain 32: $1005-1010,2016$
80. Harati Y, Gooch C, Swenson M, Edelman S, Greene D, Raskin P, Donofrio P, Cornblath D, Sachdeo R, Siu CO and Kamin M: Double-blind randomized trial of tramadol for the treatment of the pain of diabetic neuropathy. Neurology 50: 1842-1846, 1998

81. Freeman R, Raskin P, Hewitt DJ, Vorsanger GJ, Jordan DM, Xiang $J$ and Rosenthal NR; CAPSS-237 Study Group: Randomized study of tramadol/acetaminophen versus placebo in painful diabetic peripheral neuropathy. Curr Med Res Opin 23: 147-161, 2007.

82. Ghita MA, Caruntu C, Lixandru D, Pitea A, Batani A and Boda D: The quest for novel biomarkers in early diagnosis of diabetic neuropathy. Curr Proteomics 14: 86-99, 2017.

83. Caruntu C, Negrei C, Boda D, Constantin C, Caruntu A and Neagu M: Biotechnological advances for diagnosis of peripheral diabetic neuropathy. Rom Biotechnol Lett 19: 9846-9858, 2014.

84. Alsaloum M, Estacion M, Almomani R, Gerrits MM, Bönhof GJ, Ziegler D, Malik R, Ferdousi M, Lauria G, Merkies IS, et al: A gain-of-function sodium channel $\beta 2$-subunit mutation in painful diabetic neuropathy. Mol Pain 15: 1744806919849802, 2019.

85. Mendelson WB: A review of the evidence for the efficacy and safety of trazodone in insomnia. J Clin Psychiatry 66: 469-476, 2005.

86. Keppel Hesselink JM and Schatman ME: EMA401: An old antagonist of the AT2R for a new indication in neuropathic pain. J Pain Res 10: 439-443, 2017.

87. Tesfaye S: PL37: A new hope in the treatment of painful diabetic neuropathy? Pain Manag 6: 129-132, 2016.

88. Ghadiri-Anari A, Mozafari Z, Gholami S, Khodaei SA, Aboutorabi-Zarchi M, Sepehri F, Nadjarzade A, Rahmanian M and Namiranian N: Dose vitamin D supplementations improve peripheral diabetic neuropathy? A before-after clinical trial. Diabetes Metab Syndr 13: 890-893, 2019.

89. Căruntu C, Negrei C, Ghiță MA, Căruntu A, Bădărău AI, Buraga I, Boda D, Albu A and Brănişteanu D: Capsaicin, a hot topic in skin pharmacology and physiology. Farmacia 63: 487-491, 2015.

90. Căruntu C and Boda D: Evaluation through in vivo reflectance confocal microscopy of the cutaneous neurogenic inflammatory reaction induced by capsaicin in human subjects. J Biomed Opt 17: 085003, 2012.

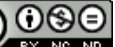

This work is licensed under a Creative Commons Attribution-NonCommercial-NoDerivatives 4.0 International (CC BY-NC-ND 4.0) License. 